\title{
MESTRADO ACADÊMICO EM ENFERMAGEM: INTERFACES DE SUA CRIAÇÃO NA PERSPECTIVA ECOSSISTÊMICA ${ }^{a}$
}

\author{
Masters degree in nursing: interfaces of its creation through the ecosystemic \\ perspective
Másteres académicos en enfermería: enfoque ecosistémico en las interfaces de su creación

Naiana Alves Oliveira

Hedi Crecencia Heckler de Siqueira²

\section{RESUMO}

Objetivou-se tecer as interfaces do Programa de Pós-Graduação em Enfermagem, Stricto sensu, curso de Mestrado Acadêmico, em uma Universidade pública do extremo sul do país, na perspectiva ecossistêmica, a partir da voz dos docentes pioneiros. Tratase de pesquisa qualitativa histórica construída por meio do método da história oral com os três docentes pioneiros do programa e levantamento documental. Os dados encontrados expressaram a seguinte temática: Criação do curso de pós-graduação stricto sensu - Mestrado Acadêmico. 0 estudo possibilitou conhecer como ocorreu a criação do curso de pós-graduação stricto sensu - Mestrado Acadêmico, o envolvimento, os significados de ser pioneiro e os desafios enfrentados pelos pioneiros. Conclui-se que o programa contribuiu expressivamente para a produção do conhecimento em enfermagem e saúde, para o seu desenvolvimento e para a qualificação de futuros docentes e pesquisadores, e estimulou e estimula a prática de ações interligadas, conectadas, em sintonia com o saber em Enfermagem.

Palavras-chave: Enfermagem. Educação de pós-graduação em Enfermagem. História. Ecossistema.

\begin{abstract}
It aims to weave the interfaces of the Post-Graduate Program in Nursing, stricto sensu, Master Degree course at a public university in the extreme south of the country, on an ecosystemic perspective, from the voice of pioneer teachers. This is a historical qualitative research built through the oral history method with the three pioneer teachers of the faculty program and documentary survey. The data found expressed the following theme: The Creation of a Post-Graduation Course stricto sensu in Master Degree. The study allowed the knowledge in understanding how occurred the creation of a post-graduation stricto sensu in Master Degree, the involvement, the meanings of being pioneers and the challenges faced by the pioneers. It is concluded that the program contributed significantly to the production of knowledge in nursing and health, its development and qualification of future teachers and researchers, stimulated and still encourages the practice of interconnected actions, linked, synchronized with the knowledge in nursing.
\end{abstract}

Keywords: Nursing. Education, Nursing, Graduate. History. Ecosystem

\section{Resumen}

El objetivo es tejer las interfaces del Programa de Postgrado en Enfermería, en stricto sensu, curso de Maestría Académica, en una universidad pública en el extremo sur del país, en la perspectiva ecosistémica, a partir de la voz de los docentes pioneros. Se trata de una investigación cualitativa, histórica, construida por el método de los profesores de historia oral con tres pioneros de la encuesta del programa y documental. Los resultados expresan las siguientes temáticas: creación del curso de posgrado stricto sensu. El estudio ha permitido conocer cómo fue la creación de los estudios de posgrado Máster Académico, la participación, los significados de ser los pioneros y los retos que enfrentan los pioneros. Se concluye que el programa ha contribuido significativamente a la producción de conocimiento en enfermería y salud, el desarrollo y la cualificación de los futuros docentes e investigadores, estimula y fomenta la práctica de acciones coordinadas, conectadas en línea con el conocimiento en enfermería.

Palabras clave: Enfermería. Educación de Postgrado en Enfermería. Historia. Ecosistema 


\section{INTRODUÇÃO}

A Enfermagem é uma ciência que se expressa na arte do cuidado ao outro, mas o espaço/território/ambiente (ETA) do seu trabalho realiza-se em um cenário de movimento que se transforma de maneira contínua. Nesse panorama, um dos ETA que proporciona esta transformação é o recinto acadêmico, mais propriamente, na formação de pós-graduação stricto sensu dos profissionais de enfermagem.

Entende-se que a enfermagem é uma prática profissional socialmente instituída e com um saber fundamentado na ciência/conhecimento próprio, e desenvolvese por meio de capacitações/habilidades e aprendizagens profissionais específicas. Essas, ao interagirem entre si, interferem no pensar e agir do outro, constroem relações capazes de mudar e transformar o ambiente em que atuam.

Dessa forma, é por meio da ciência, do conhecimento, da construção de saberes e da transformação da realidade, que o ser humano se transforma, reinterpreta o mundo onde vive e modifica suas relações com o meio ambiente e com o seu semelhante. ${ }^{1}$ Portanto, esse conhecimento transformador encontra-se intimamente relacionado com a configuração do processo formativo empenhado pelos pioneiros da pósgraduação stricto sensu dos profissionais de enfermagem. A mudança e a transformação se encontram diretamente conexas às competências, habilidades, atitudes de indivíduos críticos, independentes, com autonomia e capacidade de reflexão sobre a realidade da saúde e todos os elementos constituintes do ETA em que atuam.

Nessa acepção, retomar uma sociedade influenciada pelo desempenho de um grupo social significa visualizar os valores construídos ao longo da história desse grupo. ${ }^{1}$ Os indivíduos a ele pertencentes não somente fazem parte dessa história, mas construíram uma verdadeira identidade do grupo social, no qual se inseriram. Entretanto, esse mesmo grupo social, por meio do princípio da reciprocidade/circularidade ecossistêmica imprimiu nesse grupo pioneiro da criação de pós-graduação stricto sensu dos profissionais de enfermagem as suas peculiaridades.

Conhecer e resgatar essa história em suas diferentes faces significa trilhar os caminhos empreendidos pelos pioneiros da proposta da criação dos cursos de pós-graduação stricto sensu, inicialmente, talvez, considerada utópica, visionária ou no mínimo, audaciosa. ${ }^{1}$ Todavia, o ser humano, sujeito da história de um grupo social, ao manifestar a característica do comprometimento com o processo de transformação pessoal e social' ${ }^{1}$ e ao revelar união/coesão com o grupo empreendedor da ideia, tem a capacidade de desvendar potencialidades, habilidades transformadoras e, até mesmo superar-se nas suas fragilidades.

Nessa linha de pensamento, compreende-se que a perspectiva ecossistêmica traz, no seu conjunto teóricofilosófico, os princípios que elucidam as transformações que se processam nos espaços sociais. 0 processo contínuo de interação dos elementos constituintes desse ETA permite modificações constantes porque se constroem por meio da interdependência, parceria, cooperação e influência mútua, buscando harmonia e sustentabilidade.

Salienta-se que o curso de Enfermagem e Obstetrícia, da Universidade Federal do Rio Grande (FURG), atualmente denominado Escola de Enfermagem, foi criado em agosto de 1975 em uma universidade federal da região sul do país, na cidade de Rio Grande, no estado do Rio Grande do Sul. Em outubro de 2001, foi aprovado e recomendado o curso de pósgraduação stricto sensu - Mestrado Acadêmico em Enfermagem, na referida escola e, em abril de 2002, tiveram início as atividades acadêmicas.

0 objetivo desse artigo é tecer as interfaces da criação do curso de Mestrado Acadêmico do Programa de Pós-Graduação em Enfermagem (PPGEnf) da atual Escola de Enfermagem (EEnf) da FURG, na voz dos docentes pioneiros, na perspectiva ecossistêmica.

\section{MÉTODO}

Pesquisa de natureza qualitativa que utilizou como referencial metodológico a História Oral Temática (HOT) e pesquisa documental com base no paradigma ecossistêmico. Conforme as etapas da HOT, método de coleta de dados desenvolvido na pesquisa, realizaram-se as entrevistas, a transcrição dos depoimentos gravados, a textualização e a transcriação. A HOT é considerada um recurso metodológico, pois abriga palavras e confere sentido social às experiências individuais e coletivas. ${ }^{2}$

A entrevista em HOT foi realizada com os docentes pioneiros participantes da história de criação do PPGEnf stricto sensu - Curso de Mestrado Acadêmico (CMA), da atual EEnf/ FURG, no período de agosto a dezembro de 2010, no prédio da EEnf/FURG. Os critérios de inclusão dos docentes na pesquisa foram: ser docente participante da história de criação do CMA da atual EEnf/FURG; ser docente da Pós-Graduação em Enfermagem da atual Escola de Enfermagem da FURG; aceitar participar da pesquisa; permitir a gravação da entrevista; assinar o Termo de Consentimento Livre e Esclarecido (TCLE) em duas vias e a Carta de Cessãob.

A seleção dos sujeitos processou-se a partir do primeiro coordenador do PPGEnf stricto sensu, que indicou o par subsequente e, assim, sucessivamente. Assim, os atores sociais do estudo foram pioneiros participantes ativos da construção do Mestrado Acadêmico em Enfermagem da atual EEnf da FURG. Os sujeitos do estudo constituem um grupo formado por três enfermeiros doutores, dois dos quais realizaram estágio de pós-doutorado no exterior. Atualmente, um dos docentes está aposentado, mas todos são docentes permanentes do PPGEnf da FURG, casados e tem idade acima de 50 anos. 
0 projeto foi encaminhado e aprovado pelo Comitê de Ética em Pesquisa da área da Saúde da FURG, sob parecer N ${ }^{\circ}$ 100/2010. Foram observados todos os aspectos que envolvem a pesquisa com seres humanos, de acordo com a Resolução No 196/96 do Conselho Nacional de Saúde do Ministério da Saúde e o Código de Ética dos Profissionais de Enfermagem de 2007, sendo que os participantes assinaram o TCLE.

Os depoimentos obtidos por meio das entrevistas foram gravados, e, depois disso, os testemunhos orais foram transformados em texto escrito para torná-los disponíveis para a pesquisa. Para tanto, essa transformação para a forma escrita necessitou das etapas de transcrição, textualização e transcriação $0^{2}$. A fase de transcrição envolveu o processo de mudança do estágio oral para o código escrito; a fase de textualização correspondeu à etapa do estágio oral para um caráter narrativo; a transcriação foi a última fase da transcrição, na qual foi recriado o texto na sua plenitude. Após essa fase, ocorreu a validação do conteúdo da entrevista pelos sujeitos. Ressalta-se que, de acordo com a HOT, os depoentes assinaram a carta de cessão, autorizando, assim, a publicação de seus nomes civis para a construção do estudo². Paralelamente, utilizou-se a pesquisa documental para auxiliar na compreensão e reconstituição dessa história ${ }^{3}$.

Para a análise dos dados, realizou-se a busca de categorias para a compreensão do texto ${ }^{4}$. Para tanto, os relatos orais foram submetidos a várias leituras para a identificação dos pontos mais significativos atinentes às diferentes faces da história da criação do PPGEnf stricto sensu, da EEnf/FURG pelos docentes pioneiros, na perspectiva ecossistêmica.

No macroestudo, evidenciaram-se as temáticas: Criação do curso de pós-graduação stricto sensu - Mestrado Acadêmico e Mudanças e transformações na atual EEnf/FURG e sociedade Riograndina. Ressalta-se que, para a construção deste artigo, optou-se pelo tema Criação do curso de pós-graduação stricto sensu - Mestrado Acadêmico em Enfermagem e respectivos subtemas: Experiências dos pioneiros na criação do curso de pós-graduação stricto sensu - Mestrado Acadêmico em Enfermagem; o envolvimento dos pioneiros no processo de criação; Significados de ser pioneiro; e Os desafios enfrentados pelos pioneiros.

\section{RESULTADOS E DISCUSSÃO}

A Enfermagem, como ciência do cuidado, realiza seu trabalho, nos diferentes espaços que ocupa, em um cenário de movimento que se transforma a todo momento. Esse movimento transformador ancora-se no ser humano que nele exerce o seu pensar e agir. Entende-se o ser humano como um ser perspicaz, carregado de pontos energéticos variáveis e ondulações vibratórias, em conformidade com seu pensar, sentir e fazer. Cada um demonstra a sua força energética e suas vibrações ondulatórias, com base nas suas habilidades, de acordo com suas peculiaridades e experiências pessoais 5 .

Nessa acepção, a mudança e a transformação do espaço acontece à medida que as forças energéticas constituintes de determinado ETA são capazes de unir-se e se convergir em torno de objetivos comuns, o que exige seres humanos competentes, dedicados, solidários, cooperativos e defensores de ideias comuns e de construir algo em conjunto ${ }^{6}$. Um dos ETA que conseguiu proporcionar essa transformação foi o recinto acadêmico, do PGEnf da EEnf/FURG. Os três, únicos doutores enfermeiros, do então departamento de enfermagem, no ano de 2000, reuniram as suas energias para criar a pós-graduação Stricto sensu CMA em Enfermagem.

Os três doutores de Enfermagem, Professora Marta Regina Cezar-Vaz, Professora Valéria Lerch Lunardi e Professor Wilson Lunardi Filho, ao retornarem à FURG, com a titulação de Doutores, iniciaram o traçado de uma trajetória capaz de atender o espírito inquietante que o conhecimento/saber da ciência de Enfermagem havia implantado no seu ser. 0 seguinte relato mostra:

Quando nós concluímos o doutorado, primeiro a professora Marta Vaz, depois eu e depois o Wilson, nós começamos a nos mobilizar. A nossa ideia era dar o retorno para a instituição, e no sentido de não simplesmente, ir embora. Começamos a juntar esforços e pensar como nós faríamos (Professora Valéria Lerch Lunardi)

Nós tínhamos esse estímulo de querer criar o curso de mestrado como uma possibilidade nova, porque, depois de quinze anos como docente na graduação, nós sentíamos uma necessidade de fazer alguma coisa além de simplesmente continuar na graduação (Professor Wilson Lunardi Filho).

Na criação do mestrado, nós fizemos um mutirão. Eu lembro que foi até um mutirão na casa da professora Valéria e do Wilson, com a Maria Tereza Leopardi. Eu lembro que alguns foram com ela, e alguns foram sozinhos. Eu vou sempre. Eu lembro que, na época, era eu, Wilson e Valéria e Maria Tereza Leopardi. Não sei se teve mais alguém. Eu custo a lembrar, pois eu lembro que era sempre esse envolvimento para a construção dessa proposta. Depois, teve uma leitura. Não lembro bem, se foi da Rosita Saupe (Professora Marta Regina (ezar-Vaz).

A ideia de criar o CMA em Enfermagem poderia atender a diversos aspectos que preocupavam os três: ser algo gratificante, tanto no aspecto pessoal quanto no profissional, ao próprio Departamento de Enfermagem e à 
sociedade Riograndina; uma oportunidade para os profissionais locais, regionais e nacionais prosseguirem na sua formação e qualificação profissional; oferecer retorno palpável à instituição que oportunizou e investiu na sua qualificação profissional; proporcionar crescimento para a área da Enfermagem e consolidação na formação docente.

Para dar concretude a essa inquietação, foi necessário empreender uma grande mobilização, tanto no Departamento de Enfermagem como nos demais órgãos da FURG envolvidos com a pós-graduação, e conseguir sensibilizar doutores de outros departamentos para compartilhar essa ideia e unir-se para a sua defesa.

Ao vencer esses primeiros impasses e após as devidas negociações, foram exploradas as próximas etapas: formulação da proposta, observando cuidadosamente as exigências da CAPES. Assim, a ideia, inicialmente abstrata, começou a ser delineada de forma mais concreta:

Na época (da criação do mestrado), nós éramos poucos doutores. Quando mandamos a proposta, nós éramos três professores do departamento de enfermagem, atualmente, Escola de Enfermagem: a professora Marta Vaz, que tinha terminado (o doutorado) em 97, 96, a Valéria, em 97, e eu, em 98. (Professor Wilson Danilo Lunardi Filho).

Eu não lembro exatamente, mas eu acho que nós usamos muito o modelo da própria UFSC para criar a nossa proposta (de mestrado) e mostrá-la à professora Alacoque, com quem nós tínhamos mais proximidade. Depois, a gente foi mostrar para a professora Hedi, pensando já em concluir seu doutorado, a professora Ana Baisch, a professora Maria Cristina. Tinha alguns outros professores que faziam doutorado e nós até colocamos na proposta que seriam possibilidades (Professora Valéria Lerch Lunardi).

Os depoimentos nos mostram que a proposta de criação do Mestrado Acadêmico da FURG esteve atrelada ao modelo da Universidade Federal de Santa Catarina. Ressalta-se que a referida Universidade foi muito importante para a formação pós-graduada da Enfermagem na FURG, que iniciou por meio do curso de pós-graduação lato sensu, no qual se formaram 35 alunos, Especialistas em Projetos Assistenciais, no período de 1997 a 2005.

Percebe-se que o ponto de partida para o CMA iniciou com os convênios realizados com a UFSC, por meio da Rede de Pós-Graduação em Enfermagem da Região Sul - REPENSUL que possibilitou a qualificação de enfermeiros no contexto dos serviços de saúde e visou o desenvolvimento da pós-graduação da Enfermagem no sul do país, ${ }^{7}$ com os Mestrados Expandidos e para o oferecimento da $\mathrm{PG}$ lato sensu. As relações construídas com essa instituição, através da REPENSUL, Mestrado Expandido e a PG na FURG, certamente, foram de grande valia e permitiram aproximar as ideias para o caminho de uma possível proposta para concretizar a sua aprovação e iniciar a PG, em nível de stricto sensu - curso de Mestrado Acadêmico.

0 Professor Wilson Danilo Lunardi Filho relata que, na época da criação do curso, os docentes doutores envolvidos eram poucos. Além disso, enfatiza que houve a necessidade de agregar docentes doutores de outros departamentos da instituição para a proposta de criação do mestrado.

Nós começamos a buscar, na universidade, quem poderia fazer parte do nosso programa. Então, nós tínhamos uma enfermeira, que era a professora Ana Baisch, doutora em Farmacologia [...], e a professora Maria Cristina Soares, fisioterapeuta, e o professor Raul, doutor em epidemiologia, da medicina [...] Convidamos o professor Tabajara, que era da estatística, que participou do programa.

Como egressos da UFSC, os três pioneiros da criação do curso de mestrado de Enfermagem conseguiram, graças à proximidade de ideias, o apoio e estímulo da Professora Alacoque Lorenzini Erdmann, então coordenadora da Pós-graduação em Enfermagem da UFSC e que, pela sua disponibilidade, sempre esteve e está disposta a nortear a melhor opção a ser perseguida. Os três pioneiros, pela sua perspicácia e sabedores da necessidade agregadora, conseguiram contar com ideias da Professora Hedi Crecencia Heckler de Siqueira, que estava em fase de conclusão do doutorado, mas já era vista como uma provável docente do CMA.

Além disso, foi preciso encontrar profissionais da própria instituição, professores permanentes, para compor a proposta, e, em relação ao corpo docente, o grupo ficou assim constituído: Aloísio Ruscheinski, Ana Luiza Muccillo Baisch, Maria Cristina Flores Soares, Marta Regina Cezar Vaz, Nágila Caporlíngua Giesta, Pedro Lúcio de Souza, Tabajara Lucas de Almeida, Valeria Lerch Lunardi, Wilson Danilo Lunardi Filho, Rosita Saupe e Zuleica Maria Patrício (as duas últimas, como professoras colaboradoras, pertencentes à UFSC).

0 Programa de Pós-Graduação em Enfermagem (PPGEnf) Stricto sensu CMA na EEnf da FURG foi recomendado pelo Conselho Técnico Científico da CAPES, nos dias 03 e 04 de outubro de 2001, conforme consta no Processo No. 23001.000273/2001-39, do Diário Oficial da União (DOU) de 29 de janeiro de 2002 e iniciou as atividades em abril de 2002.

[...] nós conseguimos a aprovação, e o programa começou em 2002 [...] (Professora Valéria Lerch Lunardi). 
Esse fato marcante na história da Enfermagem do Rio Grande tornou realidade um grande sonho, um desejo expresso por um grupo de doutores em Enfermagem da FURG, que visava a produção do conhecimento, a necessidade de instrumentalização dos enfermeiros docentes e profissionais da área da saúde para uma prática que atendesse os interesses de saúde dos indivíduos e da população e qualificasse os profissionais enfermeiros para atuação no ensino e para a prática profissional. Dessa forma, as atividades docentes, com a primeira turma constituída de 11 mestrandos, iniciaram no primeiro semestre de 2002.

No que se refere ao envolvimento dos docentes pioneiros no processo de criação da pós-graduação stricto sensu CMA, o Professor Wilson Danilo Lunardi Filho referiu a satisfação de ter feito parte dessa construção e o contentamento em possibilitar a formação pós-graduada em nível de Mestrado Acadêmico na área da Enfermagem/Saúde, vendo a criação desse curso como uma nova possibilidade:

Como docente [...] eu sempre achei muito boa a experiência de ter feito o mestrado, gostei muito de construir o mestrado. Gostei muito do trabalho que fiz. [...] Foi uma coisa bem gratificante (Professor Wilson Danilo Lunardi Filho).

A proposta de criação do CMA teve um significado muito forte para a maioria dos docentes envolvidos, pois permitiria a expansão do ensino em Enfermagem na região, realidade conquistada, algo antes não imaginado, conforme os depoimentos da Professora Valéria Lerch Lunardi:

\section{[...] pensando na criação do curso de pós-graduação, serviu para expandir os nossos horizontes e pensar em algo que, talvez, fosse até inimaginável, antes [...]}

Considerando o significado da Enfermagem na época da criação do PPGEnf da FURG, no depoimento da Professora Marta Regina Cezar-Vaz, percebe-se a importância da Enfermagem na formação pós-graduada. A cultura de um grupo social representa o conjunto dos modos de vida criados e transmitidos de uma geração para outra, entre os membros de uma determinada sociedade ${ }^{8}$ :

A enfermagem tem uma constituição para mim [...] é um processo de ensino-aprendizado [...] enquanto seriedade nessa produção do conhecimento [...].

Um sistema organizado, constituído por diferentes elementos, do qual cada parte influencia e também é influenciada em uma constante troca, revela a necessidade de compreender e conceber todos os desenvolvimentos e trocas que se processam no todo, sob o olhar sistêmico e, assim, perceber a sua importância ${ }^{9}$. Desta maneira, existem muitas propriedades nos sistemas que não podem ser descritos separadamente e se fundamentam em três premissas básicas: os sistemas existem dentro de sistemas; os sistemas são abertos, recebem e se influenciam mutuamente; realizam intercâmbio infinito. Entretanto, se este intercâmbio cessa, o sistema se desintegra, pois as funções de um sistema são dependentes de sua estrutura ${ }^{10}$.

As interaç̧ões entre os elementos constituintes da realidade, ou seja, do ETA em que se situam, são capazes de formar a verdadeira identidade do grupo, pois "a identidade é percebida como o produto da história pessoal e individual, que reflete as experiências passadas" 11:827. Nessa acepção, a identidade profissional do enfermeiro que atua na docência pós-graduada pode ser caracterizada por uma rede de significados, construídos e constituídos pelo indivíduo e pelo grupo social no qual está inserido ${ }^{12}$. Quanto mais integrado, energizado e inter-relacionado estiver nas suas ações maior será a probabilidade de obter um produto de qualidade.

Eu acho que nós sempre tivemos uma identidade muito grande com a profissão, um orgulho muito grande de nos identificarmos como enfermeiras. Eu exerço a função de professora universitária, mas sou enfermeira e tenho orgulho de ser enfermeira [...] não ficamos acomodados e cada uma com sua própria dimensão [...] me sinto extremamente orgulhosa de a enfermagem (pósgraduada) estar hoje com conceito 4 (Professora Valeria Lerch Lunardi).

O mestrado propiciou mais consolidação na minha formação enquanto professora de pósgraduação, me fortaleceu enquanto professora na graduação também, e ainda mais, de ver o quanto eu consigo fazer hoje aquilo que eu digo que faço [...] (Professora Marta Regina (ezar-Vaz).

Com a finalidade de entender com mais profundidade os problemas que assolam a sociedade atual, as reflexões devem envolver desde a articulação entre os distintos campos do conhecimento, e assim apreender a dinâmica da sociedade-natureza, e considerar o processo de transformação do conhecimento até a construção do novo saber e a própria complexidade ambiental como um todo. Nesse sentido, preconiza-se um novo modelo de conhecimento, baseado na razão aberta, crítica e criativa ${ }^{13}$, para a construção de um saber ambiental ampla, comprometida com a objetivação do ser, mas também com a apropriação subjetiva da realidade que o cerca. 
[...] é um processo de ensino-aprendizado [...] 0 ensino-aprendizado, não somente enquanto profissão, mas enquanto vida. Enquanto ser humano. Então, para mim, por isso que eu digo que é mistura, que é uma química, é uma substância que eu não consigo separar [...] Ela está enquanto produção de conhecimento, ela está enquanto seriedade nessa produção de conhecimento [...] (Professora Marta Regina Cezar- Vaz).

A fala da professora Marta Regina Cezar-Vaz leva a entender que o espaço/território/ambiente no qual se vive e produz se manifesta como um todo inter-relacionado, interdependente e reciprocamente influenciável ${ }^{12}$. Na sua visão, os aspectos da vida, do ensino-aprendizagem, da profissão, da construção do conhecimento, são totalidades. Então, é nessa totalidade que as mudanças e as transformações devem ser produzidas em benefício da própria profissão, mas, também e, especialmente, considerando o próprio ser humano que vive e produz nesse espaço. Quanto mais ajustado e realizado se encontrar consigo mesmo e com os que compartilham desse ambiente mais saudável e harmonioso, maior, num sentido amplo, será a sua produção.

Conforme a fala da Professora Valéria Lerch Lunardi,

[...] nossa universidade é uma universidade jovem, com poucos programas de pós-graduação, poucos programas com mestrado e doutorado, e o nosso programa tem vários professores com pósdoutorado e a própria qualificação do nosso corpo docente, tem sido uma luta cotidiana, no sentido de reconhecimento e valorização da profissão, no sentido de avançar para uma ciência da enfermagem [...].

Essa fala demonstra, claramente, a preocupação dos docentes pioneiros na qualificação do corpo docente da atual Escola de Enfermagem e do PPGEnf da FURG. Nesse contexto, na perspectiva ecossistêmica, o sistema possui a característica dinâmica assinalada por ações criativas, flexíveis, inter-relacionadas e inovadoras que se modificam constantemente, e instituem processos transformadores nas relações produzidas pelos diferentes elementos que compõem determinado sistema, ${ }^{7}$ aqui representado pelo ETA do PPGEnf da FURG. Nesse contexto, um sistema representa

[...] um conjunto de objetos unidos por alguma forma de interação ou interdependência, qualquer conjunto de partes unidas entre si pode ser considerado um sistema, desde que as relações entre as partes e o comportamento do todo sejam o foco de atenção [...]. 10:280
A característica principal dos docentes pioneiros foram os interesses em comum, ou seja, foram movidos pelo desejo por uma Enfermagem mais qualificada, inovadora, interrelacionada e, por isso, uniram os esforços e se organizaram em torno desse alvo, no espaço da FURG.

Sabe-se que um sistema organizado é constituído por diferentes partes, conduz a uma constante permuta, revela a necessidade de compreender e conceber todos os desenvolvimentos e trocas que se processam no todo sob o olhar sistêmico, e, assim, perceber a sua importância. Assim, 0 ambiente pode ser definido como um conjunto de relações complexas e sinérgicas geradas pela articulação dos processos físicos, biológicos, termodinâmicos, econômicos, políticos e culturais. ${ }^{10}$

Considerar o ambiente, no seu sentido ecossistêmico, é compreendê-lo como uma estrutura dinâmica, composta de elementos que se inter-relacionam e se modificam constantemente em busca da construção do novo, da mudança, ${ }^{10}$ da transformação social.

Eu acho que deveríamos fazer um marketing maior da enfermagem [...] é a oportunidade de mudar o significado da enfermagem [...] a gente não deixa aflorar nossa importância;

[...] o nosso programa é conhecido no Brasil, a gente é conhecido nos lugares [...] a imagem da enfermagem se fortaleceu como um curso forte na universidade [...]" (Professor Wilson Lunardi Filho).

0 trabalho desenvolvido na formação profissional de enfermagem, por meio de um curso de mestrado acadêmico, permite maior visibilidade das atividades desenvolvidas porque o fluxo de informações utiliza-se de vias, cuja velocidade imprime um sentido mais direto entre os pares que constituem a realidade da pós-graduação stricto sensu. Desta forma, a divulgação do conhecimento construído projeta-se rapidamente em âmbito nacional e internacional.

Além disso, os 106 mestres que concluíram as suas dissertações, nesses dez anos da criação do CMA em Enfermagem, completos em outubro de 2011, são oriundos de diversos e longínquos espaços sociais e, ao retornarem, são capazes de exercer a docência com maior qualificação profissional, divulgar os conhecimentos construídos, e, certamente, estão preparados a continuar na construção do conhecimento/saber. A sua inserção social nos diversos espaços permite rápida disseminação do conhecimento desenvolvido e possibilita e incentiva a continuidade da construção do saber na área da Enfermagem.

Nessa acepção, outro aspecto a considerar são os trabalhos científicos produzidos, as dissertações e os inúmeros artigos publicados em periódicos nacionais e internacionais, oriundos da produção no CMA. Esse conjunto de fatores é capaz de desencadear uma visibilidade mais consistente do CMA em 
Enfermagem da FURG. Nesse mesmo patamar expositivo, é preciso acrescentar, como fatores favoráveis à visibilidade do CMA, os eventos que são desenvolvidos pelos professores e mestrandos, a publicação de livros e as reuniões programadas pela CAPES com a participação de todos os cursos de pósgraduação stricto sensu do país.

Os desafios enfrentados pelos pioneiros podem ser visto sob diversos ângulos e diferenciadas dimensões. Uma das dimensões poderia ser a pessoal, em relação ao compromisso diante da postura a ser tomada como pessoa que usufruiu tempo para ampliar os seus conhecimentos e buscar retorno, beneficiando a instituição que opor tunizou o aperfeiçoamento intelectual. Os pioneiros da criação da pós-graduação de Enfermagem stricto sensu manifestaram essa preocupação, e, certamente, essa foi a mola propulsora para se empenharem nesse trabalho árduo, mas profícuo.

0 depoimento da Professora Valéria Lerch Lunardi deixa claro o compromisso que se assume ao avançar no conhecimento:

[...] sentido de nós termos o compromisso com nossa instituição, no sentido de nos qualificar, não apenas em termos de títulos, mas como nós retornamos para a instituição [...] o primeiro desafio foi a criação do programa [...] fazer parte de pósgraduação implica inúmeras exigências, da mesma forma agora com o doutorado: conseguimos conceito 4, mas estamos pensando no conceito $5 \mathrm{e}$ isso implica muito trabalho, muita articulação, muitos esforços, muitas noites sem dormir, fins de semana [...].

Os desafios relatados pelos docentes foram apontados a partir de suas vivências que caracterizaram suas relações sociais. 0 depoimento dos docentes pioneiros, armazenado em suas memórias, é um recurso fundamental para a construção e elaboração da narrativa histórica e para a determinação de valores culturais a serem transmitidos às novas gerações na formação pós-graduada e, assim, transformá-la, de forma permanente em memória coletiva, dando continuidade nas conquistas alcançadas nos dias atuais. É o sentido da fala do Dr. Lunardi:

[...] corresponder com relação a essa avaliação que pesa muito que a gente tem que estar sempre em função da avaliação da CAPES [...] nosso programa conseguiu quatro nessa última avaliação, a chance de subir é grande, mas vai depender dos nossos esforços, porque a chance de cair também é muito grande, se a gente (docentes) não corresponder a produção que tem que ter [...] Então, os desafios [...] de continuar formando os recursos humanos, e de qualificar, $e$ também o desafio de avançar [...]" (Professor Wilson Danilo Lunardi Filho).

No sentido do ser individual, pertencente a um grupo social, todos juntos, estamos presentes em um sistema interrelacionado 7.0 ambiente, ao se transformar, incorpora também os indivíduos, seus valores e sua cultura. Ao considerar a relação construída para um novo ponto de vista do conhecimento e da ação social, contribuindo para uma nova relação entre o homem e a natureza, torna-se evidente que o aprofundamento de processos educativos no âmbito ecossistêmico apresenta-se como uma condição indispensável para construir uma nova racionalidade ambiental que possibilite interações capazes de estabelecer relações entre a sociedade e a natureza, entre 0 conhecimento científico e as intervenções empíricas, entre o pensar e fazer enfermagem.

Nessa acepção, (re)visitar uma sociedade influenciada pelo desempenho de um grupo social, de enfermeiros Doutores, retornando à instituição com interesse comum de realizações significativas para si, para o grupo de enfermeiros e a sociedade Riograndina, denota conhecer os valores construídos ao longo da história desse grupo.

Transportando analogicamente esses conceitos para o ambiente acadêmico e as relações entre os demais elementos que integram essa realidade, neste caso, a formação da pósgraduação stricto sensu em Enfermagem, tem-se que o grupo permitiu e permite a inter-relação e a interdependência dos elementos, ambas favoráveis para a qualificação do profissional enfermeiro e a construção do saber em Enfermagem. Assim, a dimensão sistêmica possibilitou e possibilita interferências no meio, produziu e produz influências, modificações, manifestas de forma dinâmica às particularidades dos indivíduos que integram as interfaces do grupo social em construçãa ${ }^{14}$.

Essas interfaces imprimem particularidades específicas em cada ETA porque as relações recíprocas correspondem a características próprias de cada elemento constituinte desse espaço. Portanto, esse grupo de doutores conseguiu e continua projetando, atualmente com acréscimo de novos integrantes, esse modelo com as especificidades próprias do ETA no qual convivem e produzem.

\section{CONCLUSÕES}

Os depoimentos dos docentes pioneiros revelam que a criação do curso de pós-graduação stricto sensu - Mestrado Acadêmico foi um grande desafio para um pequeno grupo de docentes doutores à época, mas que, ao longo dos dez anos de sua história, a formação de um corpo docente sólido possibilitou não apenas a sua continuidade, mas levou a ideais mais auspiciosos, criando o "novato" curso de doutorado.

Concebe-se, ainda, que os docentes pioneiros associaram, ainda, a criação do programa de pós-graduação do 
curso de mestrado acadêmico à criação do Departamento de Enfermagem, que certamente representou a mola propulsora para a criação da Escola de Enfermagem, em 2008, que oportunizou maior autonomia aos seus anseios e esperançosos empreendimentos.

A autonomia da Escola de Enfermagem, como uma das 13 unidades acadêmicas da FURG, foi evidenciada pela maioria dos sujeitos como um dos resultados positivos da criação do CMA. Essa condição favoreceu a continuidade da construção de valores e das transformações na forma de pensar e agir em Enfermagem.

As inter-relações e os vínculos de docentes de outras unidades acadêmicas de ensino da FURG foram ratificados como contribuidores para o desenvolvimento do programa na atual Escola de Enfermagem, servindo, também, para dar maior visibilidade à Enfermagem na Instituição. A visibilidade é um fator indispensável a um grupo que busca realizar mudanças e transformações no seu ETA, e, ao ser divulgada entre outras unidades, as relações são passíveis de desvendamento e crescimento célere.

Desse modo, o reconhecimento, a valorização e a visibilidade da profissão foram apontados como fatores importantes da história da pós-graduação stricto sensu, pelos pioneiros do CMA, pois a Enfermagem tornou-se mais reconhecida e com maior destaque no âmbito da Universidade e em âmbito local, regional e nacional.

A qualificação dos profissionais de enfermagem, do fazer social, e o compromisso para uma Enfermagem consolidada e reconhecida nacional e internacionalmente foram aspectos demonstrados pelos docentes e evidenciados pela formação de 106 mestres em Enfermagem e suas respectivas dissertações de mestrado e pela produção de múltiplos artigos científicos publicados em periódicos nacionais e internacionais.

Enfim, a história de criação do programa de pósgraduação sricto sensu CMA contribuiu para o ensino em Enfermagem na FURG e sociedade Riograndina, visto a estimulação dos atores sociais envolvidos nessa construção. Entretanto, é com a continuidade do ensino em Enfermagem, em uma instituição respeitada e responsável, que a construção do conhecimento continuará a contribuir para a qualificação de recursos humanos em Enfermagem, de forma interligada e, especialmente, por meio de seu "novato" Curso de Doutorado em pleno funcionamento. Essa interligação entre todos os elementos que fazem parte da totalidade do CMA, ao oferecer suas interfaces próprias, podem possibilitar as fortalezas necessárias para um porvir cada vez mais auspicioso da Enfermagem da FURG.

\section{REFERÊNCIAS}

1. Oliveira NA. A pós-graduação em enfermagem da Universidade Federal do Rio Grande: percorrendo os caminhos de sua história [dissertação de mestrado]. Rio Grande (RS): Escola de Enfermagem, Universidade Federal do Rio Grande; 2012.

2. Bom Meihy JCS, Holanda F. História oral: como fazer, como pensar. São Paulo: Contexto, 2007.

3. GIL, A. C. Métodos e técnicas de pesquisa social. $5^{\circ}$ ed. São Paulo: Atlas, 2007.

4. Minayo MCS. Pesquisa social: teoria, método e criatividade. $21^{\mathrm{a}}$ ed. Petrópolis (RJ): Vozes; 2010.

5. Silva RMCRA, Pereira ER, Santo FHE, Silva MA. Cultura, saúde e enfermagem: o saber, o direito e o fazer crítico-humano. Rev. Eletr. Enf. [Internet]. 2008; [citado 2009 out 23]; 10(4): 1165-71. Disponível em: <http://www.fen.ufg.br/revista/v10/ n4/v10n4a30.htm>

6. Capra F. A teia da vida: uma nova compreensão científica dos sistemas vivos. 10ª ed. São Paulo: Cultrix; 2006.

7. Oliveira NA, Thofehrn MB, Cecagno D, Siqueira HCH, Porto AR. Especialização em projetos assistenciais de enfermagem: contribuições na prática profissional dos egressos. Texto Contexto Enf. 2009 out/dez; 18(4): 697-704.

8. Chiavenato I. Teoria geral da administração. $7^{a}$ ed. São Paulo: Campus; 2004.

9. Galindo WCM. A construção da identidade profissional docente. Psicologia: ciência e profissão. 2004; 24(2): 1423.

10. Siqueira HCH. As interconexões dos serviços no trabalho hospitalar - um novo modo de pensar e agir [tese de doutorado]. Florianópolis(SC): Programa de Pós-Graduação em Enfermagem, Universidade Federal de Santa Catarina; 2001.

11. Mello R, Furegato ARF. Teoria ego-ecológica e o estudo da identidade social - aplicabilidade em pesquisas de enfermagem. Esc Anna Nery Rev Enferm. 2011 out/dez; 15(4): 825-32.

12. Santos MC, Siqueira HCH, Silva JR. Saúde coletiva na perspectiva ecossistêmica: uma possibilidade de ações do enfermeiro. Rev. Gaúch. Enferm. 2009 dez; 30(4): 437-44.

13. Leff E. Epistemologia ambiental. São Paulo: Cortez; 2001.

14. Claval PA. Geografia cultural. $3^{\text {a }}$ ed. Florianópolis (SC): UFSC; 2007. 


\section{NOTA}

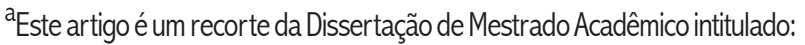
"A Pós-Graduação em Enfermagem da Universidade Federal do Rio Grande: Percorrendo os caminhos de sua história" de Naiana Alves Oliveira, defendida em 31/08/2011, no Programa de Pós-Graduação em Enfermagem da Universidade Federal do Rio Grande (FURG).

${ }^{b}$ A carta de cessão é um documento que confere ao autor o consentimento para a publicação do nome civil dos entrevistados, importante instrumento para este estudo por tratar-se de uma pesquisa histórica. ${ }^{2}$ 